\title{
Calculating operational value-AT-Risk (OpVaR) IN A RETAIL BANK
}

\author{
Ja'nel Esterhuysen \\ Investec Bank Ltd and School of Economics, North West University \\ Paul Styger \\ School of Economics, North-West University
}

Gary van Vuuren

Financial Institutions, Fitch Ratings and School of Economics, North West University

\begin{abstract}
The management of operational value-at-risk (OpVaR) in financial institutions is presented by means of a novel, robust calculation technique and the influence of this value on the capital held by a bank for operational risk. A clear distinction between economic and regulatory capital is made, as well as the way OpVaR models may be used to calculate both types of capital. Under the Advanced Measurement Approach (AMA), banks may employ OpVaR models to calculate regulatory capital; this article therefore illustrates the differences in regulatory capital when using the AMA and the Standardised Approach (SA), by means of an example. Economic capital is found to converge with regulatory capital using the AMA, but not if the SA is used.
\end{abstract}

JEL G21, C15, 16

\section{1}

\section{Introduction}

During the early 1990s, the two biggest risks for banks were market and credit risk and a great deal of attention was focused on measuring and managing these risks (Harmantiz, 2003: 1). Today's turbulent financial markets, growing regulatory environments and increasingly complex financial systems, however, have led risk managers to measure and manage risks other than market and credit risks, which have come to be known collectively as operational risk (Harmantiz, 2003: 1). Infrastructure failures (e.g. information technology, terrorist attacks), fraud (e.g. rogue trading), and legal and regulatory risks (e.g. fines) have become the motivators behind the move to proactively manage operational risk in large financial institutions (Dev, 2006: 12).

Although credit and market risks are well understood, and are more likely to damage an institution, operational risk remains an enigma for risk managers, owing almost entirely to lack of understanding of the nature of the risk (Dev, 2006: 12). Unlike market and credit risks, which tend to be confined to specific areas of the business, operational risk is inherent to all businesses and processes: it is a broader concept than merely operations or back-office risks. Operational risk is anything but well understood (Dev, 2006: 12): there is disagreement even about specific contingencies that should be considered 'operational risks' (for example, should legal risk, tax risk and reputation risk be included?). The debate is more than simply academic (Harmantiz, 2003: 2), as the outcome defines the entire initiative for managing operational risk.

Acknowledgement of the above, coupled with a burgeoning awareness of the importance of operations to business, led the Basel Committee on Banking Supervision to include an explicit capital requirement for operational risk when 
revising the Basel Capital Accord. The revision began in 1998, and the first consultative document was published in June 1999 (Cruz, 2002: 271). The introduction of this additional capital requirement (BIS, 2005: 33) took a good part of the financial services industry, those who did not believe this would happen, by surprise (Olsson, 2002: 255). Under the 1988 accord, it was assumed that the credit risk charge implicitly covered other risks, including operational risk. From January 2008, the new capital guidelines are going to require those financial institutions that elect to use more risk-sensitive modelling approaches to reporting capital to implement robust systems for collection and tracking data (Dev, 2006: 13). As a result, most financial institutions have begun to devote significant resources to identifying, measuring, analysing, reporting and mitigating this potentially catastrophic risk class. The aim of all these institutions is to implement a framework that will meet the requirements of the New Basel Capital Accord, including, amongst others, operational loss data collection, operational loss data tracking and a robust internal risk-control system (Dev, 2006: 13).

Within this new framework, banks will implement one of three approaches for calculating minimum regulatory capital for operational risk. These approaches are the Basic Indicator Approach (BIA), the Standardised Approach (SA) and the Advanced Measurement Approach (AMA), with complexity increasing from first to last (Esterhuysen, 2006: 132). The new Capital Accord also describes a model for calculating economic capital against extreme risks under the AMA, a major contribution to the quantification of operational risk (Esterhuysen, 2006: 133). Banks therefore calculate two types of capital, regulatory and economic, for operational risk, with the consequent possibility that either too much or too little capital provision is made (Belmont, 2004: 121).

Banks usually employ their own internal capital models (Cruz, 2002: 271), which include value-at-risk (VaR) models for market risk. With the AMA, the Basel Committee will allow banks to use these internal VaR models to calculate minimum regulatory capital for operational risk, if proof of model accuracy can be provided to regulators (Esterhuysen, 2006: 221). The aim of this article is to explain how VaR for operational risk is calculated and how this may be used to calculate the minimum regulatory capital charge for operational risk under the AMA. The way in which this capital calculation method aligns economic and regulatory capital more closely is also demonstrated. Actual operational loss data from a South African retail bank is used to demonstrate how regulatory capital is calculated with AMA based on a VaR model. The difference in regulatory capital, calculated with and without an underlying VaR model, is also explored.

The remainder of this article is structured as follows: Section 2 provides a brief theoretical background on the Basel Committee's proposals for calculating regulatory capital for operational risk, as well as a short discussion on VaR for operational risk. Section 3 explains the methodology employed in this research, and includes a description of a retail bank as well as a brief description of the method for calculating VaR for operational risk. The results of the calculation of regulatory capital based on VaR and gross income is discussed in Section 4. Section 5 concludes the article.

\section{2}

\section{Literature review}

Two types of capital play a role in safeguarding banks against operational risk, namely economic and regulatory capital, defined as follows:

Regulatory capital is the amount of capital a regulator requires a bank to hold to safeguard it against operational risk and is based on the proposals of the Basel Committee with its New Basel Capital Accord. Economic capital is the amount of capital a financial institution itself deems necessary to operate normally, given its risk profile and its state of controls (Mueller, 2005: 5).

As these definitions indicate, regulatory capital is calculated for operational risk based on the proposals of the Basel Committee in its New Basel Capital Accord. These proposals are based on three approaches, which include the following: 
1. The Basic Indicator Approach (BIA). This approach uses gross income as a proxy for operational risk, with the capital charge equal to 15 per cent of the average of gross income for the last three years.

2. The Standardised Approach (SA). This approach also employs gross income as a proxy measure for operational risk, but in this case it is divided into eight standard business lines, each with a different risk weight factor to calculate capital.

3. The Advanced Measurement Approach (AMA). In the AMA approach, the regulatory capital requirement is the risk measure generated by the bank's internal operational risk measurement system (model) (BIS, 2005: 221).

Banks must adopt certain criteria based on gross income to calculate regulatory capital for operational risk for both the BIA and the SA. The AMA banks' own internal operational risk measurement models may be used to calculate regulatory capital. Internal operational risk measurement models predominantly involve calculating the VaR of operational risk in order to determine the amount of regulatory capital required for operational risk (Cruz, 2002: 12). When calculating VaR for operational risk there are three basic principles that should be kept in mind (Cruz, 2002: 34), which include the following:

- Time horizon: The time horizon (period) is, for example, the length of time over which an institution plans to calculate VaR. The period proposed by The Basel Committee is one year.

- The confidence level: the level of confidence at which the institution will make the estimate. Popular confidence levels are 95 per cent and 99 per cent.

- The currency unit: the currency which will be used to dominate the value at risk.

A variety of models exists for calculating VaR for operational risk. Each model has its own set of assumptions, the most common of which is that historical operational loss data is the best estimator of future changes (Cruz, 2002: 35). Chenobai et al. (2004: 111) note that the three most frequently-used models for calculating VaR for operational risk are the historical data model, the variance-covariance model and the loss-distribution model. Belmont (2004: 12) and Cruz (2002: 113) conclude that the loss distribution model is the most accurate for calculating operational risk VaR in most banks.

Chapelle et al. (2005: 14) and Alexander (2003: 110) propose an adapted version of the standard loss distribution approach (LDA), deriving the aggregated loss distribution by convolving the frequency distribution of loss events and the severity distribution of a loss given event (see Figure 1). Chapelle et al. (2005: 14) have emphasised that mixing two empirical loss distributions models the severity distribution is calculated more accurately than with a single empirical loss distribution. The model proposed by Chapelle et al. (2004: 14) is divided into two parts: the first with losses below a selected threshold (considered as normal losses), and the second with large, potential abnormal losses. Both parts are estimates with the usual density functions for fat-tailed distributions. In addition, the loss distribution approach models the frequency using a Poisson ${ }^{1}$ distribution, with parameter $\mu$ equal to the number of observed losses during the whole period (Alexander, 2003: 23). Chapelle et al. (2004: 14) note that it is consequently possible to combine the calibrated frequency and severity distribution to compute the aggregated loss distribution by running Monte Carlo simulations. The procedure may be described as follows:

1. Generate 10,000 Poisson random variables representing the number of events for the 10,000 simulated periods.

2. For each period, generate the required number of severity random variables (that is, if the simulated number of events for period $k$ is $X$, then $k X$ severity losses need to be generated) and to sum these to obtain the aggregated loss for the period. 
3. Obtain the vector representing the 10,000 simulated periods. When sorted, the smallest value thus represents the 0.0001 quantile $(1 / 10,000)$, the second the 0.0002 quantile, and so forth, which makes the VaR for operational risk very easy to calculate.

4. The last step involves running steps 1 to 3 , for example, ten times, and evaluating the average $\mathrm{VaR}$ from these ten runs for operational risk.

Figure 1 shows these steps schematically.

To take the extreme and various rare losses into account, this model applies Extreme
Value Theory ${ }^{2}$ (EVT) to the results (Chapelle et al., 2005: 14). The advantage of EVT is that it provides a tool to estimate rare and not-yetrecorded events for a given database (Chapelle et al., 2005: 14). Chapelle et al. (2005: 15) mention further that the use of EVT emerges very similar to VaR for operational risk, except at very high percentiles, i.e. $>99.99^{\text {th }}$ percentile. As the Basel Committee (BIS, 2005: 143) recommends a confidence level of 99.90 per cent, the Monte Carlo simulation will allow this model to compute a sufficiently complete sample, including most of the extreme cases (Peters et al., 2003: 29).

\section{Figure 1}

The loss distribution approach

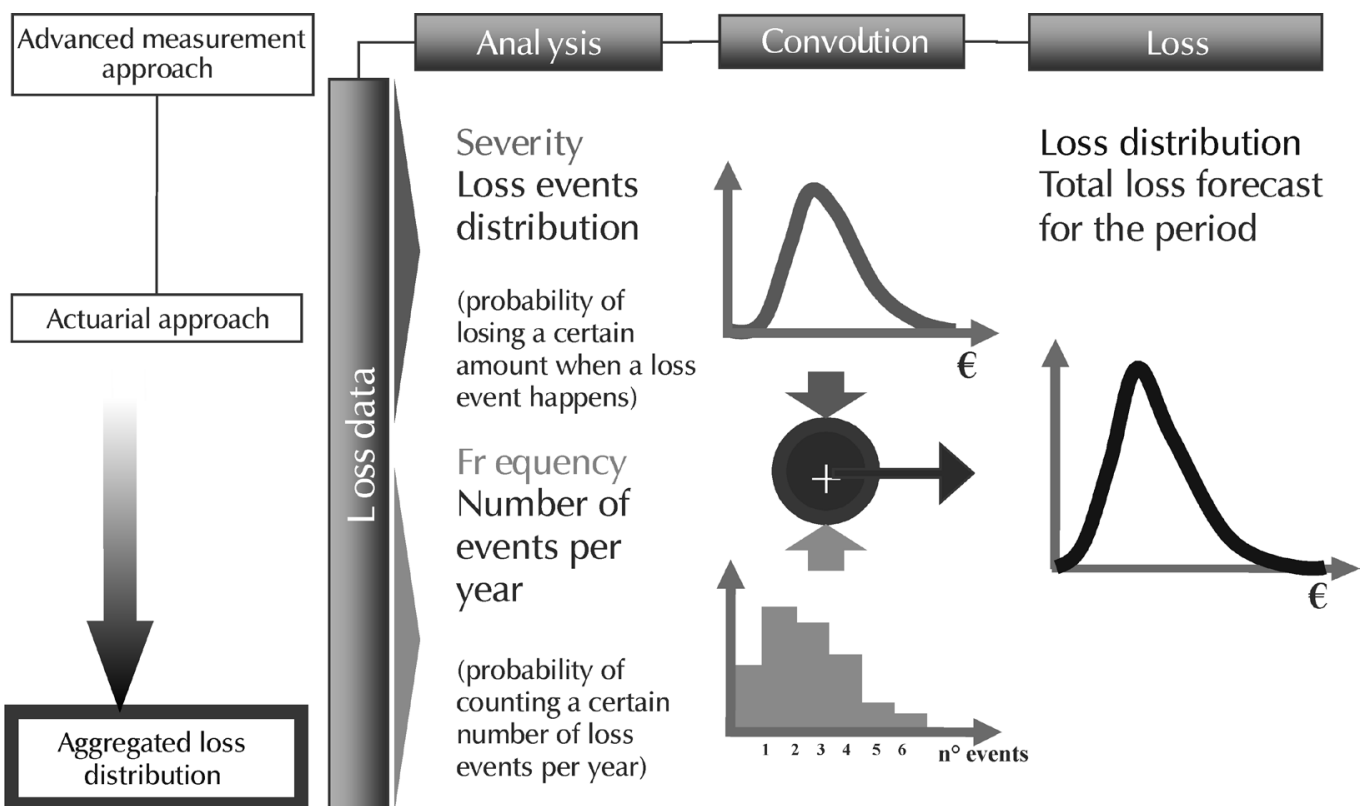

(Source: Esterhuysen, 2006: 221)

3

\section{Methodology} economic capital, but they will also be permitted to use them to calculate regulatory capital under the AMA if they can prove to their respective regulators that these models are accurate and robust. The next section explains how $\mathrm{VaR}$ is calculated for operational risk from a Standardised and Advanced approach.
To illustrate how VaR for operational risk is calculated and how regulatory and economic capital are calculated using the AMA, actual operational loss data were obtained from a South African retail bank. Real gross income 
data were also obtained (from the same South African retail bank) to demonstrate how regulatory and economic capital are calculated with the SA. Results from these calculations are discussed in Section 3.

\subsection{South African retail banks}

The bank explored is a typical South African retail bank, comprising several divisions (Esterhuysen, 2003: 134), including Compliance, Finances, Marketing, Procurement, Distribution, and Legal and Banking products, as shown in Figure 2.

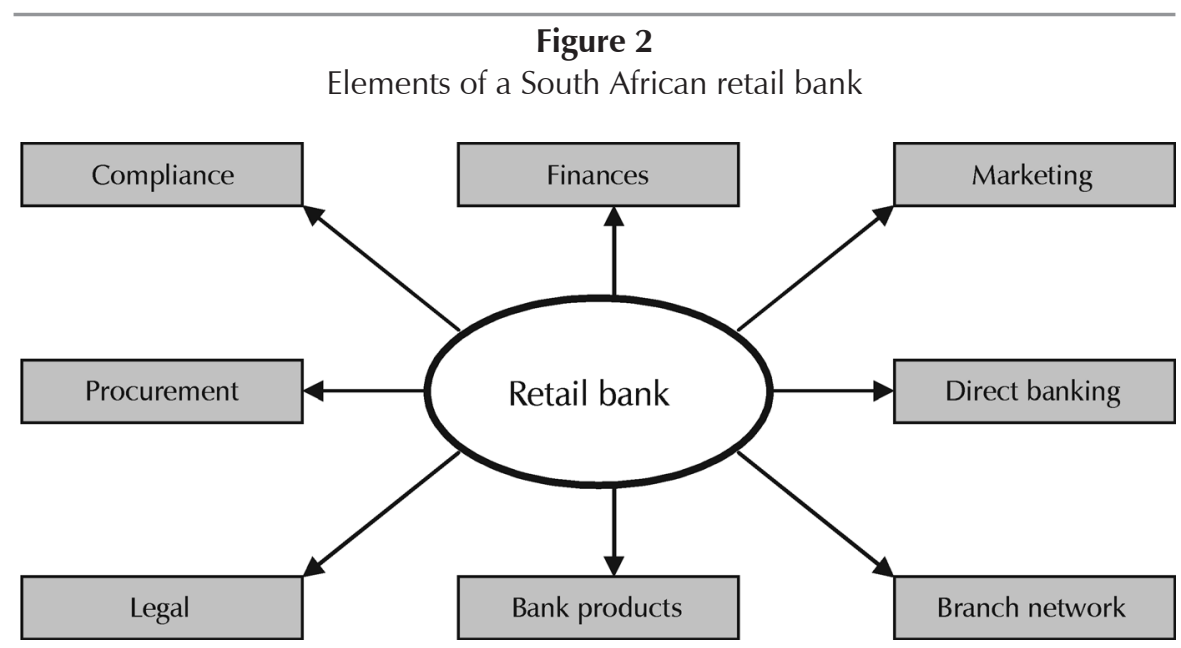

(Source: Esterhuysen, 2003: 134)

\subsection{Calculation methodology}

The method used to calculate the VaR for operational risk was the loss distribution approach (see Figure 1). It was conducted with a Microsoft Excel spreadsheet based on the principles discussed by Cruz (2003: 35-71) (see Appendix A).

\subsection{Sample data}

The data sample used includes the operational losses for the last three years, shown in Table 1.
The data also includes the gross income for the same bank for the last three years $(2003,2004$ and 2005), as shown in Table 2.

The operational loss data in Table 1 is actual data obtained from a South African retail bank and is set out from the largest to the smallest loss. These losses, recorded in 2003, 2004 and 2005, were extracted from the bank's internal operational loss database (i.e. they are regarded as internal operational loss data).

\section{Table 1}

Operational loss data (in R) from a South African retail bank

\begin{tabular}{|r|r|r|r|r|l|l|l|l|l|l|}
\hline 9669000 & 328416 & 222910 & 161333 & 118397 & 94636 & 76991 & 55476 & 15245 & 3177 & 1464 \\
\hline 5380000 & 325492 & 211048 & 154216 & 117855 & 93588 & 75745 & 45731 & 13603 & 2873 & 1250 \\
\hline 1139196 & 323414 & 207425 & 154010 & 114745 & 93085 & 75587 & 42161 & 10209 & 2626 & 1069 \\
\hline 1101618 & 319171 & 196441 & 151088 & 112393 & 92396 & 73119 & 37918 & 10000 & 2621 & 1000 \\
\hline 845663 & 303966 & 195847 & 141580 & 110535 & 92311 & 69008 & 36561 & 9472 & 2621 & \\
\hline 686724 & 299248 & 189670 & 138644 & 109561 & 87434 & 64343 & 36002 & 8000 & 2419 & \\
\hline 684420 & 296288 & 185932 & 135024 & 106718 & 86239 & 64276 & 22979 & 7661 & 2275 & \\
\hline
\end{tabular}




\begin{tabular}{|l|l|l|l|l|l|l|l|l|l|l|}
\hline 574061 & 293205 & 175863 & 132092 & 104918 & 85347 & 63471 & 21874 & 6696 & 2077 & \\
\hline 461773 & 286591 & 175668 & 128575 & 103937 & 81380 & 63009 & 21671 & 6091 & 2000 & \\
\hline 352522 & 278993 & 170182 & 126390 & 101302 & 80021 & 59948 & 21671 & 5400 & 1692 & \\
\hline 329410 & 274708 & 164826 & 118516 & 100501 & 78656 & 57316 & 17681 & 3587 & 1568 & \\
\hline
\end{tabular}

Gross income data in Table 2 are based on the definition of the Basel Committee in its new framework, where gross income is defined as net interest income plus net non-interest income, with the intention that it should be gross of any provisions; be gross of operating expenses, including fees paid to outsourcing service providers; exclude realised profits/losses from the sale of securities in the banking book and exclude extraordinary or irregular items, as well as income derived from insurance (BIS, 2005: 221).

Table 2

Gross income from a South African retail bank

\begin{tabular}{|l|r|r|r|}
\hline & \multicolumn{1}{|c|}{$\mathbf{2 0 0 3}$} & \multicolumn{1}{|c|}{$\mathbf{2 0 0 4}$} & \multicolumn{1}{c|}{$\mathbf{2 0 0 5}$} \\
\hline Net interest income plus net non-interest income* & 312009876 & 371654826 & 407765891 \\
\hline Plus operating expenses & 44328745 & 51998213 & 61558901 \\
\hline Plus provisions & 14990342 & 12896872 & 15892334 \\
\hline Minus realised profits & - & - & - \\
\hline Minus income from Insurance & 3231000 & 5689198 & 11895324 \\
\hline Gross income & 368097963 & 430860713 & 473321802 \\
\hline
\end{tabular}

* Net interest income plus non-interest income is referred to as profit from ordinary activities before goodwill amortisation, i.e. operating expenses and provisions are already included.

\section{4}

\section{Results}

This section aims to explain the VaR calculation for operational risk so that a better understanding of the management thereof may be instituted. This section will also explain how regulatory and economic capital are calculated (using both the SA and AMA approaches) as well as the role that VaR plays in the calculation of these two types of operational risk capital.

\subsection{The Standardised Approach (SA)}

The Basel Committee specifies eight business lines within the SA whereby regulatory capital is calculated by means of multiplying a beta factor $(\beta)$ with the average gross income for the last three years for each business line. The loss data used in this example is extracted from the retail division of a South African Bank and thus falls under the "retail banking" business line for which the Basel Committee proposes $(\beta=12 \%)$. Regulatory capital, based on the definition of gross income in Section 2, is then calculated as (using data obtained from Table 2):

$$
\begin{aligned}
\text { Regulatory capital }_{\mathrm{SA}} & =\frac{1}{3}\left(\sum_{\mathrm{t}=2003}^{2005} \text { Gross income }\right) \cdot \beta \\
& =\frac{1}{3}(368097963+430860713+473321802) \times 12 \% \\
& =50891219
\end{aligned}
$$


The minimum regulatory capital the bank is thus required to hold under the SA for the "retail banking" business line is R50 891219.

Economic capital is calculated for the same business line, using VaR (which employs the loss distribution approach: see Figure 1). This calculation is conducted in Microsoft
Excel, and uses the operational loss data from Table 1. Appendix A details the calculation methodology. As illustrated in Figure 1, the first step in calculating VaR for operational risk is to derive the frequency distribution for the sample in Table 1.

Figure 3

Frequency distribution

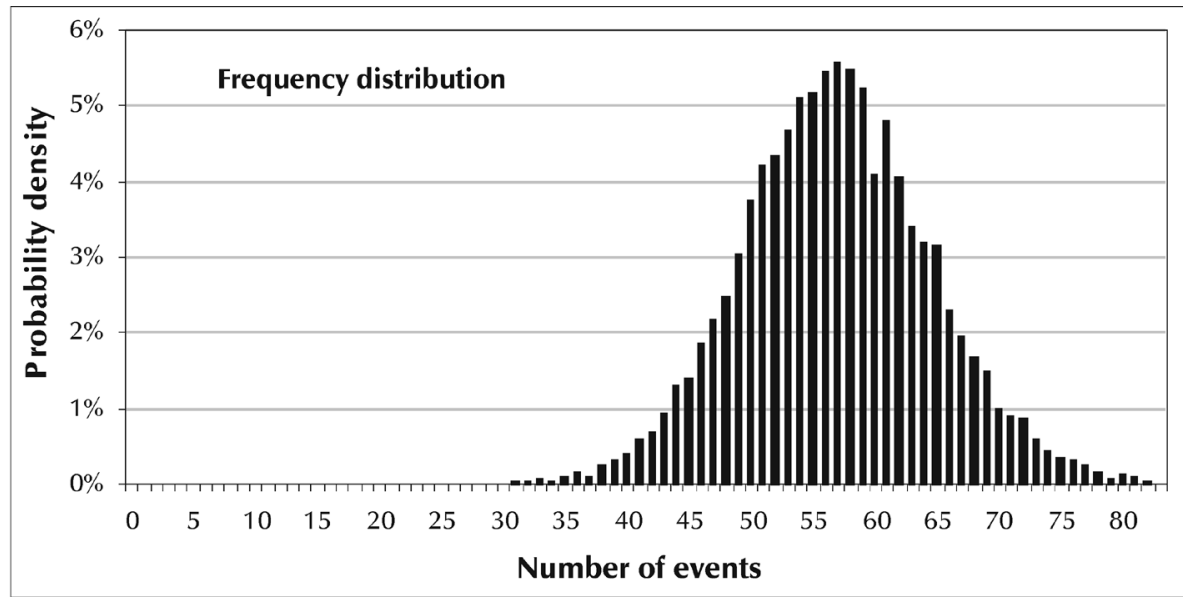

The next step in the calculation of VaR for operational risk is to derive a severity distribution for the sample in Table 1. An exponential severity distribution for the data in Table 1 is illustrated in Figure 4.

Figure 4

Severity distribution

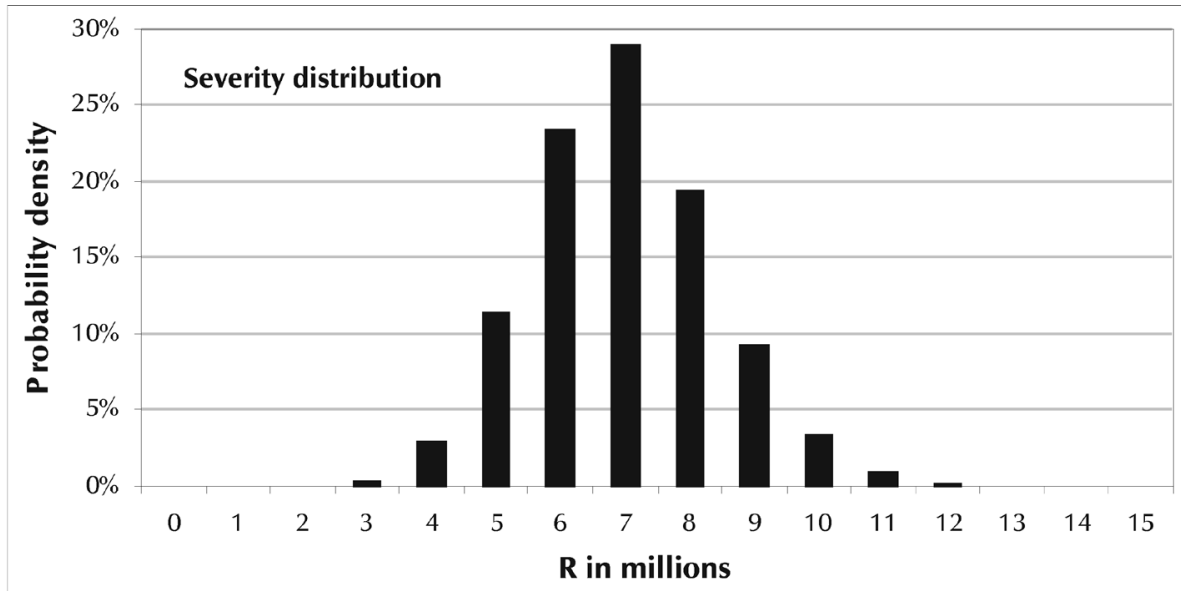


Following this, by running 5000 Monte Carlo simulations it is possible to derive an aggregated loss distribution from the simulated frequency and severity distributions, illustrated in Figure 5:

Figure 5

Aggregated loss distribution

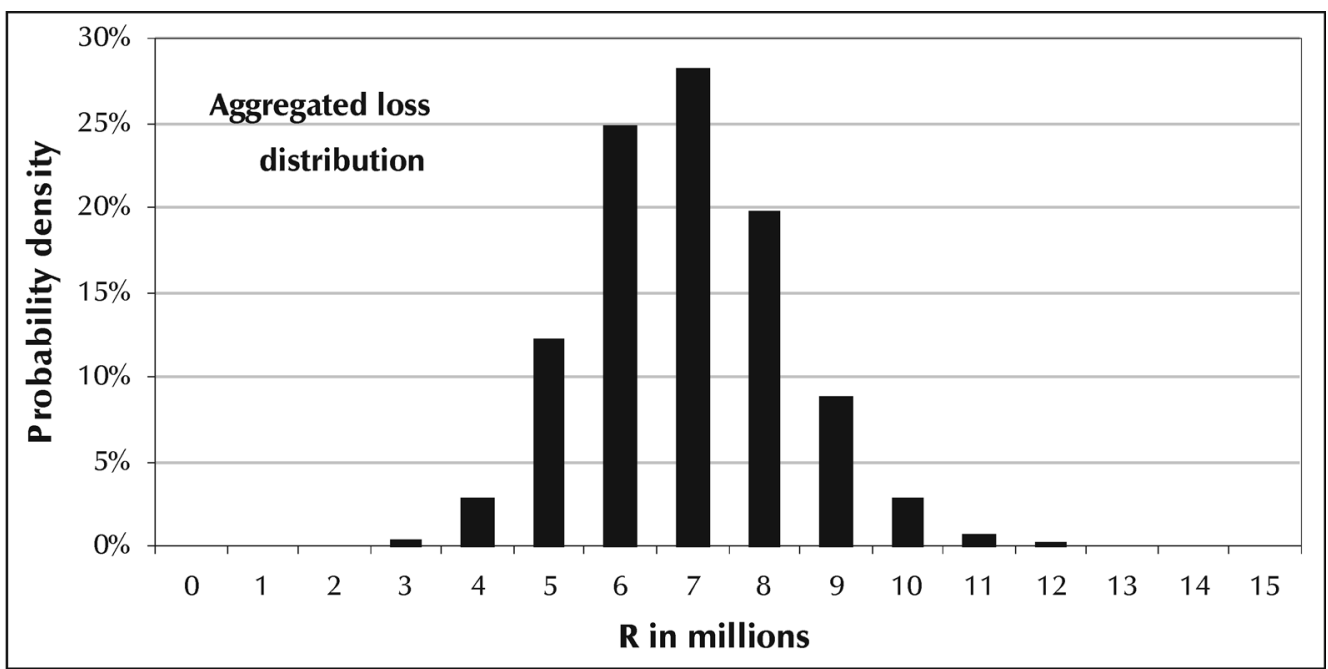

The next step is to calculate the percentiles from the aggregated loss distribution in order to determine the VaR. These percentiles are illustrated in Table 3. If the bank chooses a 99.9 per cent confidence level, it will use the 99. $9^{\text {th }}$ percentile at which confidence level VaR for operational risk is R13 384 748, the amount of economic capital the bank will hold for operational risk. If regulatory capital is calculated by means of the SA, and economic capital by means of VaR, regulatory capital will then be almost four times more then economic capital. This difference is illustrated in Figure 6.

Table 3

Percentiles

\begin{tabular}{|c|c|c|c|}
\hline Percentile & Value & Percentile & Value \\
\hline $\mathbf{9 9 . 9}$ & 13384748 & $\mathbf{7 5}$ & 9227356 \\
\hline $\mathbf{9 9}$ & 12076551 & $\mathbf{7 0}$ & 8994968 \\
\hline $\mathbf{9 5}$ & 10923061 & $\mathbf{6 5}$ & 8774800 \\
\hline $\mathbf{9 0}$ & 10276852 & $\mathbf{6 0}$ & 8559977 \\
\hline $\mathbf{8 5}$ & 9861256 & $\mathbf{5 5}$ & 8347726 \\
\hline $\mathbf{8 0}$ & 9503911 & $\mathbf{5 0}$ & 8121771 \\
\hline
\end{tabular}




\section{Figure 6}

Regulatory capital calculated on a proxy of gross income and economic capital calculated by a VaR approach

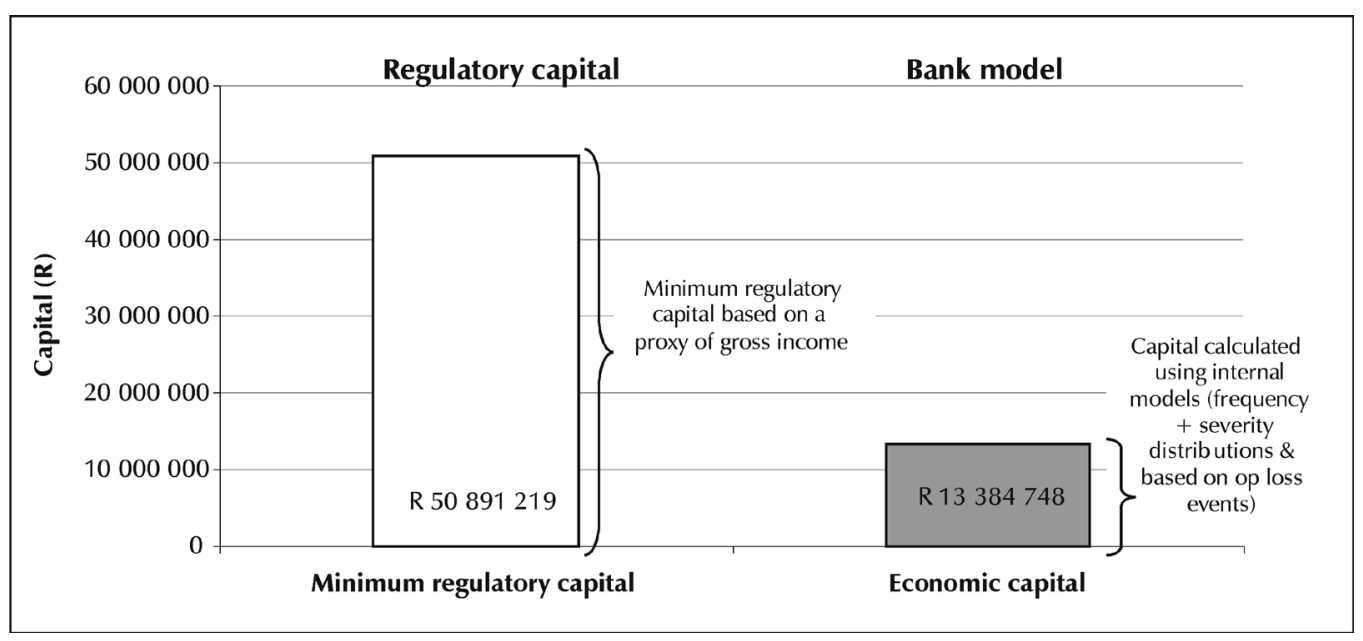

The next section describes the calculation of regulatory capital by means of the AMA, and discusses the differences when compared with calculating regulatory capital by means of the SA.

\subsection{The Advanced Measurement Approach (AMA)}

Regulatory capital calculations with the AMA permit banks to use, amongst others, a VaR approach. In Section 3.1, the minimum operational loss at a 99.9 per cent confidence level was calculated at R13 384 748, which is equal to the minimum amount of economic capital the bank will hold for operational risk. If banks are allowed to use VaR calculations to calculate regulatory capital, the amount of regulatory capital the bank will hold with AMA will also be R13 384 748, i.e. economic and regulatory capital are equal. There is a reduction of R37 506471 (R50 891219 - R13 384 748) in regulatory capital when the bank migrates from the SA to the AMA (see Figure 7).

Figure 7

Regulatory and economic capital with the AMA

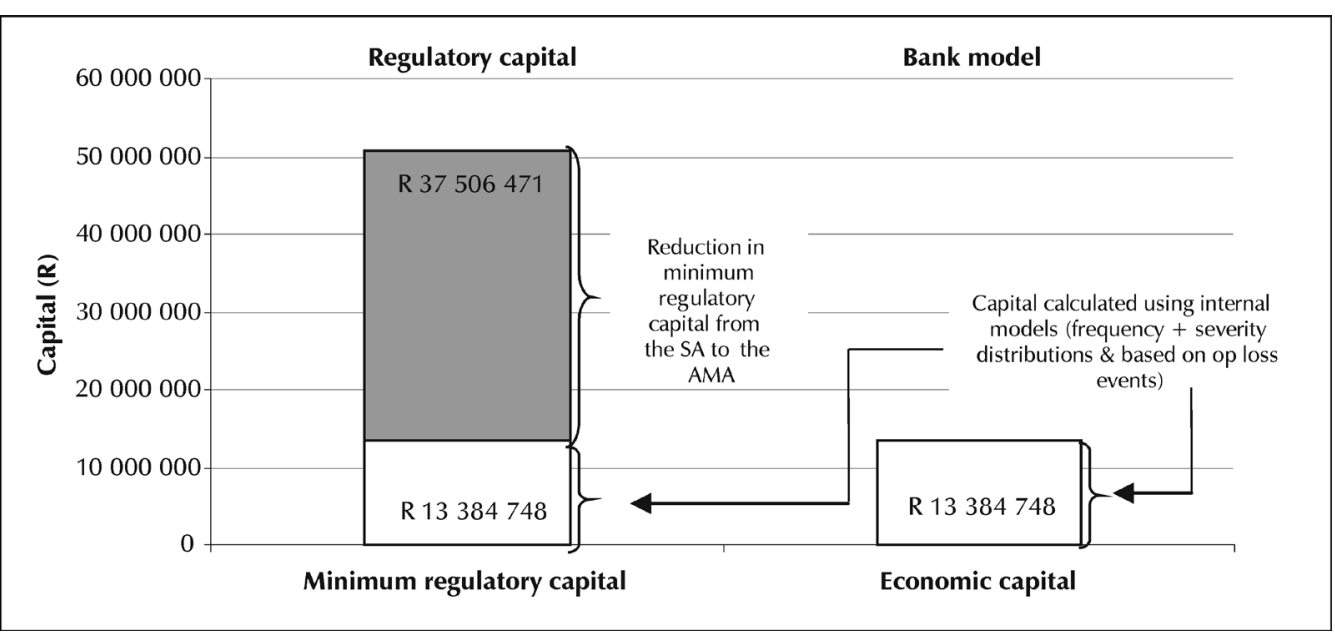




\subsection{Discussion}

The Basel Committee's intention with its operational risk capital framework is to guide banks to better align minimum regulatory capital with economic capital when a bank moves from a simple approach to a more complex approach. The example illustrates how the regulatory capital will decrease if a bank with proportionately low documented operational losses to gross income moves from the SA to the more complex AMA. It is important to note that the calculation of regulatory capital with the SA is based on gross income, which is a poor indication of the real operational risks occurring in a bank. However, this is the only proxy for operational risk offered in the Accord for a bank that is incapable of reporting operational loss data and complying with the other qualitative requirements for reporting under the AMA.

With the AMA, the Basel Committee proposes that banks use their last three years of operational loss data to calculate VaR for operational risk. If operational losses are used to calculate regulatory capital, it will also mean that banks will hold less regulatory capital if they can prevent or decrease some of their operational losses if they implement a more robust operational risk management and control environment. Consequently, banks that manage operational risk appropriately will incur a less punitive capital charge under the AMA. This is, however, not the case with the SA, as gross income is not impacted by a robust operational risk management environment.

When a bank uses VaR to calculate regulatory capital, this figure could equal economic capital if the bank were to use VaR to measure economic capital. Because VaR for operational risk is also based on past operational losses, the bank will hold regulatory capital commensurate with the size of operational risk it faces, as recorded operational losses are perhaps the best indicator of the magnitude of operational risk.

Banks might experience an increase in regulatory capital when they migrate from the SA to the AMA if they have a large number of extensive operational losses. However, their compliance with appropriate regulations will ensure that they will be holding a more representative amount of capital. This statement introduces one of the key conclusions of this article, which is that the amount of regulatory capital calculated by the AMA correlates directly with the size of operational risk faced by the bank. This is one of the advantages of calculating regulatory capital by means of VaR.

In addition, the Basel Committee states that banks must hold capital equal to their unexpected losses with the AMA if they have

Figure 8

Expected and unexpected losses

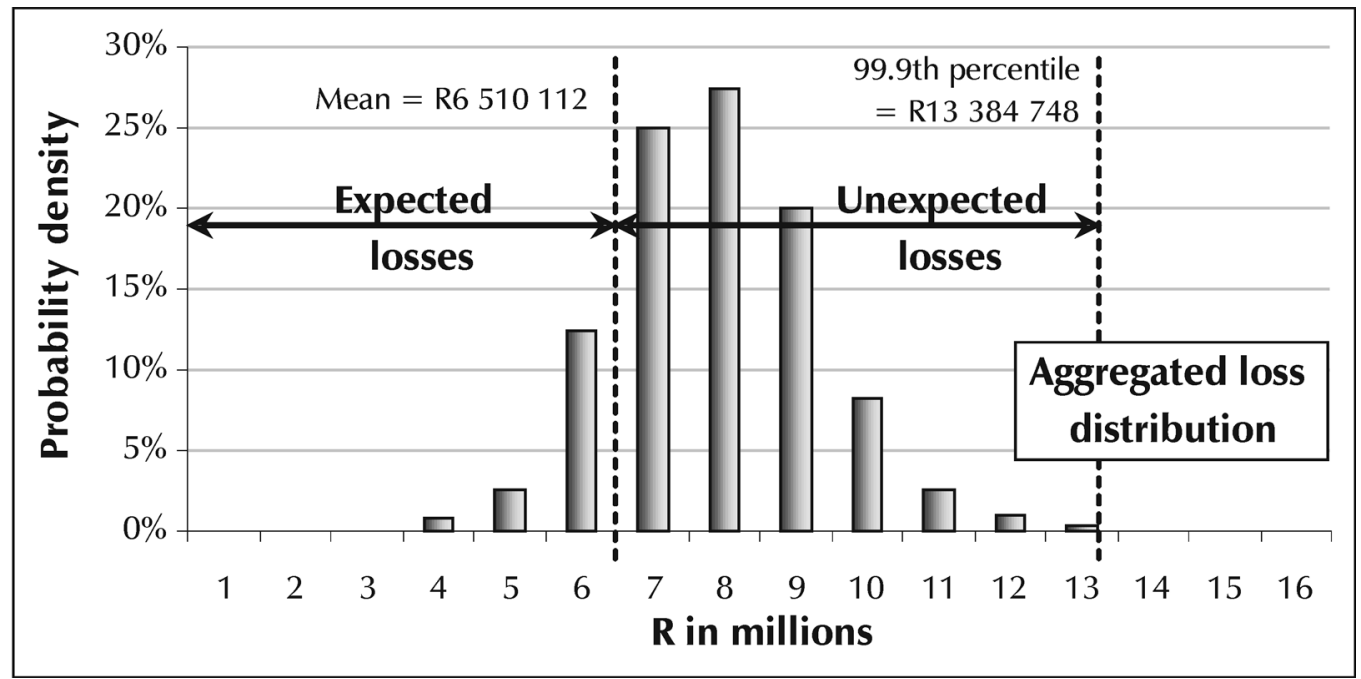


made provisions for their expected losses. Expected losses are the operational losses expected to occur at least once a year and are calculated as the mean of the loss distribution. In the current example, this is calculated by estimating the average loss resulting from the 5000 Monte Carlo Simulations. Unexpected losses are the difference between the $99.9^{\text {th }}$ percentile value (or the VaR value) and the expected loss (mean) as illustrated in Figure 8.

Note that, in the example, the mean of the aggregated loss distribution is not equal to the $50^{\text {th }}$ percentile (see Table 3 ). If the bank in the example made operational loss provisions equal to or greater than its expected losses, regulatory capital required under the AMA is R6 874 634, which consequently means that regulatory capital will be less than economic capital, as illustrated in Figure 9.

Regulatory capital could still equal economic capital when VaR is used to calculate regulatory capital: the two types of capital will be different only if a bank has accurately forecast and designated provisions for expected losses.

Figure 9

Regulatory capital if provisions were made

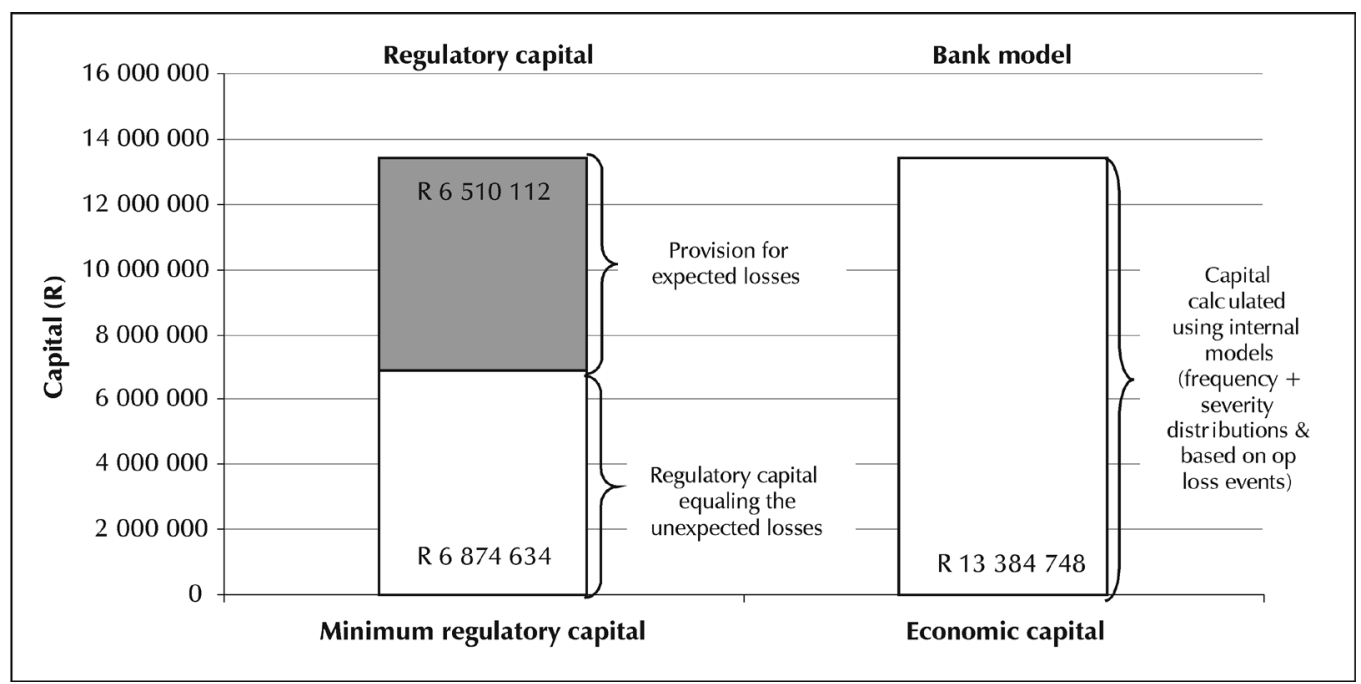

5

\section{Conclusion}

As the deadline for the implementation of the New Basel Capital Accord has recently passed, banks are focusing not only on the identification and management of operational risk, but also on the measurement thereof. Banks must be able to measure operational risk (under AMA) in order to be able to hold the requisite capital. The Basel Committee has proposed three approaches within its new framework: the Basic Indicator Approach, the Standardised Approach and the Advanced Measurement Approach. With the AMA, the Basel Committee has proposed the most prudent level of regulatory capital, which has resulted in the majority of international banks aiming to implement this approach. Further, the capital value under the AMA will be a truer reflection of the operational risk a bank faces. With the AMA, banks will be allowed to use their own internal capital models to calculate regulatory capital if they can prove to their respective regulators that these models are accurate. These models are usually value-atrisk (VaR) models, which banks use to calculate economic capital.

Banks aiming to calculate VaR for operational risk based on past operational losses have found that the challenge was not always just in the calculation, but was also in understanding the results and the management of these losses. 
This article illustrates how operational risk may be measured using VaR techniques in the calculation, as well as how this VaR figure influences the amount regulatory capital banks will hold for operational risk. Banks may hold less capital when they use the AMA to calculate regulatory capital by means of VaR, but this might not always be the case. For example, it may happen that, if a bank has experienced large operational losses in the last three years but has not experienced much growth in terms of gross income, the bank will hold more regulatory capital with the AMA than with the SA. Alternatively, the AMA may benefit banks that have accurate operational loss data that has been collected over some time; VaR can be computed from this data, which will mean not only that the amount of regulatory capital will be more aligned with economic capital, but also that banks will hold regulatory capital more aligned with the size of operational risk. The amount of regulator capital will thus be directly correlated to the size of operational risk.

Banks have to understand what is used in the VaR calculation in order to ascertain ways of decreasing this figure. The calculation of VaR for operational risk is based predominantly on recorded operational losses. Consequently, if the value and frequency of operational losses increases, operational risk VaR will increase.

It is not certain whether banks will hold less regulatory capital when they move from the SA to the AMA, but it might mean that they hold more. This, however, should not discourage banks from implementing the AMA nor from calculating regulatory capital by means of VaR, as it will ensure a more accurate regulatory capital figure. Banks will also benefit from implementing a robust operational risk management environment as this will ensure that operational losses are better controlled, implying a lower VaR for operational risk and a lower regulatory capital figure.

Additional research could address the other three factors proposed by the Basel Committee for operational risk VaR calculation, including the external operational losses database, business expertise, and scenario analysis. This article has focused only on the operational losses from the internal operational loss database.

\section{Endnotes}

1 The Poisson distribution is defined as a mathematical statement of the probability that exactly $k$ discrete events will take place during an interval of length $t$ (Alexander, 2003:15).

2 Extreme value Theory (EVT) is a statistical discipline to describe and understand quantifiable rare events. It is especially well-suited to describe the fat tails of profit and loss distributions (Alexander, 2003:2).

3 It is, of course, also possible to calculate other percentiles, for example the 99th percentile or the 95 th percentile.

\section{References}

1 ALEXANDER, C. (2003) "Statistical models of operational loss". In Operational Risk: Regulation, Analysis and Management (pp. 102-189). FT Prentice Hall: New York.

2 BANK FOR INTERNATIONAL SETTLEMENTS (BIS), Basel Committee on Banking Supervision. (2005) International Convergence of Capital Measurement and Capital Standards: A Revised Framework. November 2005. BIS, Basel, Switzerland.

3 BELMONT, B. (2004) Value Added Risk Management in Financial Institutions, (1st ed.) John Wiley \& Sons Ltd: Chichester, UK.

4 CHAPELLE, CRAMA, A., HUBNER, Y., \& PETERS, J. P. (2005) "Measuring and managing operational risk in the financial sector - an integrated framework", Working Paper, HEC Management School, University of Liege, November 2003.

5 CHERNOBAI, A., MENN, C., TRUCK, S. \& RACHEV, S. T. (2004) "A note on the estimation of the frequency and severity distributions of operational losses", Journal of Applied Probability Trust, University of California, Santa Barbara, USA, December: 13-27.

6 CRUZ, M.G. (2002) Modelling, Measuring and Hedging Operational Risk, John Wiley \& Sons Ltd: West Sussex, UK.

7 DEV, A. (2006) "Operational risk: Some issues in Basel II AMA implementation in US financial institutions", RISK, Washington, USA, April.

8 ESTERHUYSEN, J.T. (2003) "The management of operational risk in South African banks" (Thesis: MComm), Potchefstroom, South Africa: PU for CHE.

9 ESTERHUYSEN, J.T. (2006) “Managing operational value-at-risk (OPVaR) in a Banking Environment" (Thesis: DComm), North-West University, Potchefstroom, South Africa. 
10 HARMANTZIS, F. (2003) "Turbulent times focus attention on operational risk management in financial services": [Online] Available at: http:// www.lionhrtpub.com [Date of access:4 April 2005].

11 HOFFMAN, D.G. (2002) Managing Operational Risk: 20 Firm Wide Best Practice Strategies, John Wiley \& Sons Ltd: Chicago, USA.

12 MUELLER, H. (2005) "Economic capital Recent Market Developments and Current Trends, paper prepared for the Society of Actuaries' Risk Management Section Council, UK, October.

13 OLSSON, C. (2002) Risk Management in Emerging Markets: How to Survive and Prosper, Prentice Hall, New York, USA.

14 PETERS, J.P., GRAMA, Y. \& HUBNER, G. (2003) "Basel II Project: computation of OpVaR", working paper, HEC Management School, University of Liège, Belgium.

\section{APPENDIX A}

\section{Calculating VaR for operational risk in Microsoft Excel}

\section{Step 1 - Simulating frequencies}

This article uses the Poisson frequency distribution to model the frequency of the operational loss data illustrated in Table 1 . It is therefore important to calculate $\lambda$. The data in Table 1 was collected over 2 years, but, as discussed, VaR is calculated over one year. Thus, if there were 144 data points over 24 months, $\lambda=57$ - the number of data points over 12 months. Figure 10 shows the requisite Excel spreadsheet with three columns labelled "Run\#", "Frequency" and "Adj Total". The "Run\#" column is a list of the number of simulations that will be performed, in this case, 5000 . In the "Frequency" column, Poisson random numbers are generated as follows:

Step 1 - Choose the Tools function on the Toolbar

Step 2 - At Tools, choose the Data Analysis function

Step 3 - Choose the random number generation function

Step 4 - Select the following:

1. Number of variables $=1$ (only one frequency per simulation)

2. Number of variables $=5000$ (the number of simulations)

3. Distribution $=$ Poisson

4. $\lambda=57$

\section{Figure 10}

Simulating frequencies in Excel

\begin{tabular}{|c|c|c|}
\hline Run \# & Frequency & Adj Total \\
\hline 1 & 62 & \\
\hline 2 & 59 & \\
\hline 3 & 57 & \\
\hline 4 & 53 & \\
\hline$\ldots$ & $\ldots$ & \\
\hline 5000 & 49 & \\
\hline
\end{tabular}


If these basic steps are followed, 5000 Poisson random variables are generated that simulate the frequency of the operational loss data in Table 1 . The next step is to model the frequency, which is done by counting how many of a specific random number there were in the 5000 simulations. For example, of the 5000 simulations, there were 7 occasions when the loss was R 0.20 when the loss was R1.18 when R2, and so on. The highest Poisson number in the test result was 82 , so only 83 rows are required, as illustrated in Table 4.

Table 4

Example - simulated frequencies

\begin{tabular}{|c|c|}
\hline Random variable & Count \\
\hline 0 & 0 \\
\hline 1 & 12 \\
\hline$\ldots$ & $\ldots$ \\
\hline 83 & 0 \\
\hline
\end{tabular}

In explanation of the above, for example, in the truncated data, there were 14 instances of 2 out of the 5000 simulations, which means that there were two days out of the 5000 simulated days on which the loss occurred 14 times per day. In order to calculate the probability, the number per day is divided by 5000 simulations, for example 14 divided by 5000 , which will be a percentage. After the above process has been carried out, the results can be graphed, as illustrated in Figure 3.

\section{Step 2 - Simulating severities}

The next step involves modelling the operational loss severity in Table 1. This is also performed in the "adj. total" column in the Microsoft Excel spreadsheet. The severity figures will also be based on random generated numbers, and will be based on the frequency for that specific simulation. For example, if the frequency states " 3 ", then three uniform random numbers should be generated to calculate the simulated severity for simulation number 10 . These uniform numbers will then be equal to $p$, i.e. the probability that helps to find the quantile in the exponential distribution function. The following example will explain the above, assuming that the following are given:

The average of all the losses $(\mu)=145.917$

$\lambda$ for exponential distribution $=\frac{1}{\mu}=\frac{1}{145.917}=6.853 \times 10^{-6}$

Cumulative exponential distribution function $x=\ln \frac{(1-p)}{-\lambda}$

To explain Figure 11, 5 randomly generated values are simulated by means of the exponential distribution, and are then added to calculate the severity for the first simulation. This can also be calculated in Excel by using the loginv function, in which $p$ is equal to the frequency of the first simulation, the location is the number of the simulation, and the scale is $\lambda$. The Excel spreadsheet then automatically calculates 5000 severities, as illustrated in Figure 12. 


\section{Figure 11}

Calculating random generated severities

\begin{tabular}{|c|c|c|}
\hline Run\# & Frequency & Adj Total \\
\hline 1 & 5 & \\
\hline
\end{tabular}

This is the value of exponential distribution calculated with the probability in 1,2 or 3 , by means of the cumulative exponential distribution function of: $x=\ln \frac{(1-p)}{\lambda}$

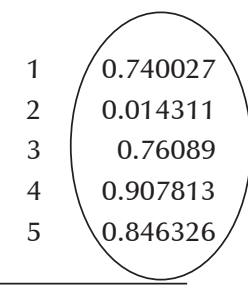

Figure 12

Simulating severities

\begin{tabular}{|r|r|c|}
\hline Run \# & Frequency & Adj Total \\
\hline 1 & 62 & 6885094 \\
\hline 2 & 59 & 9199841 \\
\hline 3 & 57 & 8307141 \\
\hline 4 & 53 & 6972763 \\
\hline$\ldots$ & $\ldots$ & $\ldots$ \\
\hline 5000 & 49 & 7955055 \\
\hline
\end{tabular}

Figure 4 is a graphical representation of the severity distribution. It is important first to choose loss bands for the data, in this case 17, R1 million bands. The severity is calculated using Excel's "frequency" function.

\section{Step 3 - Ordering the data and calculating percentiles}

The next step involves adding a column to the spreadsheet (in Figure 13 labelled "Ordered data"). The data in the "Adj Total" column is then ordered from high to low, as shown in Figure 13.

Figure 13

Ordered values

\begin{tabular}{|c|c|c|c|c|}
\hline Run \# & Frequency & Adj Total & Ordered total & $\%$ \\
\hline 1 & 62 & 6885094 & 14116282 & 99.9 \\
\hline 2 & 59 & 9199841 & 13639821 & 99 \\
\hline 3 & 57 & 8307141 & 13598795 & 90 \\
\hline 4 & 53 & 6972763 & 13573857 & 0 \\
\hline
\end{tabular}


The mean is then calculated, i.e. the average of all the 5000 aggregated values:

$$
\frac{\mathrm{R} 41128240000}{5000}=\mathrm{R} 8236448
$$

The percentile is estimated and empirical results indicate that it is best to use the $99.9^{\text {th }}$ percentile. ${ }^{3}$ The percentiles can be calculated from the ordered total in the Excel spreadsheet by using the "Percentile" function in which the "data array" is all the data in the Ordered total column and " $\mathrm{k}$ " is the required percentile (for example the $99.9^{\text {th }}$ percentile will be 0.999 ). The calculated percentile values are shown in Table 5. Choosing a confidence level leads directly to the operational VaR.

\section{Table 5}

VaR percentiles

\begin{tabular}{|c|c|c|c|}
\hline Percentile & Value & Percentile & Value \\
\hline 99.9 & 13384748 & 80 & 9503911 \\
\hline 99 & 12076551 & 75 & 9227356 \\
\hline 95 & 10923061 & 70 & 8994968 \\
\hline 90 & 10276852 & 65 & 8774800 \\
\hline 85 & 9861256 & 60 & 8559977 \\
\hline 80 & 9503911 & 55 & 8347726 \\
\hline
\end{tabular}

